\title{
Expert consensus on magnetic recanalization technique for biliary anastomotic strictures after liver transplantation
}

\author{
$\mathrm{Yu} \mathrm{Li}^{1,2,3}$, Nan Zhang ${ }^{2,3}$, Yi Lv ${ }^{1,2,3}$; Scientific Committee of the Third International Conference of Magnetic Surgery ${ }^{*}$ \\ ${ }^{1}$ Department of Hepatobiliary Surgery, the First Affiliated Hospital of Xi'an Jiaotong University, Xi'an, China; ${ }^{2}$ National Local Joint \\ Engineering Research Center for Precision Surgery \& Regenerative Medicine, Xi'an, China; ${ }^{3}$ Shaanxi Province Center for Regenerative \\ Medicine and Surgery Engineering Research, Xi'an, China \\ Correspondence to: Yi Lv. Department of Hepatobiliary Surgery, the First Affiliated Hospital of Xi'an Jiaotong University, Xi'an 710061, \\ China. Email: luyi169@126.com.
}

Submitted Nov 16, 2020. Accepted for publication Feb 26, 2021.

doi: $10.21037 /$ hbsn-20-800

View this article at: http://dx.doi.org/10.21037/hbsn-20-800

Biliary anastomotic stricture (BAS) is a common complication after liver transplantation.

Endoscopic retrograde cholangiopancreatography (ERCP) or percutaneous transhepatic cholangial drainage (PTCD) is the preferred treatment for BAS. However, these methods are helpless for completely occluded strictures. Magnetic recanalization technology (MRT), which is an application of magnetic compression anastomosis, is reported as a revolutionary way to treat BAS, and initially imply a satisfactory result for complicated cases (1-7). However, there are still no consensus reported. On the Third International Conference of Magnetic Surgery held in Xi'an, experts from various countries have discussed associated fields of MRT in treating BAS and achieved the following consensus.

\begin{abstract}
Indications and contraindications of MRT Indications

(I) Biliary anastomotic occlusion, such as bilo-biliary anastomosis and bilo-enteric anastomosis;

(II) Refractory stricture with multiple failures of ERCP or PTCD;

(III) Two biliary stricture stumps are close to the same axis.
\end{abstract}

\section{Absolute contraindications}

(I) The stricture length is $>20 \mathrm{~mm}$;

(II) A large amount of ascites or severe coagulation dysfunction, which do not allow an effective PTCD to be established;

\footnotetext{
* Members of Scientific Committee of the Third Inter-national Conference of Magnetic Surgery (Sorted Alphabetically by Last Name): Michael Avaliani, Blokhin Russian Oncology Research Center, Russian Research Centre of Surgery, Russia; Luigi Bonavina, University of Milan, Istituto di Ricovero e Cura a Carattere Scientifico Policlin San Donato, Italy; Paolo Cantù, Foundation IRCCS Ca' Granda - Ospedale Maggiore Policlinico, Università degli Studi di Milano, Milan, Italy; Michele Diana, Institut de chirurgie guidée par l'image (IHU) de Strasbourg, Strasbourg, France; Boris Dolgushin, Blokhin Russian Oncology Research Center, Russian Research Centre of Surgery, Russia; Mark Bremholm Bremholm Ellebaek, Odense University Hospital, Denmark; Takao Itoi, Tokyo Medical University, Japan; Hideaki Kawabata, Kyoto Okamoto Memorial Hospital, Japan; DongKi Lee, Gangnam Severance Hospital, Yonsei University, Korea; Erkan Parlak, Sakarya University, Turkey; Bo Wang, The First Affiliated Hospital of Xi'an Jiaotong University, China; Rong-Qian Wu, The First Affiliated Hospital of Xi'an Jiaotong University, China; Zheng Wu, The First Affiliated Hospital of Xi'an Jiaotong University, China; Xiao-peng Yan, The First Affiliated Hospital of Xi'an Jiaotong Universi-ty, China; Vitalii Zablotskii, Institute of Physics of the Academy of Sciences of the Czech Republic, Czech.
} 
(III) Presence of contraindications for ERCP or unable establishment of two magnet delivery routes;

(IV) Vital organs failure;

(V) Complicated severe non-anastomotic biliary strictures are present.

\section{Relative contraindications}

(I) Bile duct dilation is not obvious due to repeated cholangitis, or there is an angle between the upper and lower ends of the strictures;

(II) A potential risk affected by the magnetic field, such as in cases with implanted cardiac pacemakers, is present;

(III) Evident biliary leakage is present.

\section{Operative steps of MRT}

\section{Preoperative evaluation}

Abdominal ultrasound can be used as a routine examination for screening biliary strictures or as a tool for PTCD. Magnetic resonance cholangiopancreatography (MRCP) is the first choice for diagnosing biliary stricture, but it is often not accurate enough for MRT; a simultaneous imaging of biliary tract through PTCD and ERCP can not only help understand the location of the narrow site, but also accurately assess their length and local condition $(1,2)$.

\section{Preoperative preparation}

PTCD tract is used as a percutaneous delivery route. A larger PTCD catheter is gradually replaced the previous one to expand the diameter of the sinus tract. Generally, $10-16$ Fr catheters are indwelled for 2 weeks to enhance the strength of the sinus tract.

\section{Operative steps}

Two methods are present depending on whether BAS is occluded: (I) when BAS is completely occluded, a cylindrical magnet without an axial central hole is used (Figure 1A). A sheath is inserted into the PTCD tract to protect around tissues. Then, the daughter magnet is advanced into the upper end of the stricture with a pusher (Figure $1 B$ ). After successful papillary cannulation, an endoscopic sphincterotomy (EST) is performed, followed by balloon dilatation. The parent magnet is connected to the tip of the endoscope with a long thread in the channel.
The endoscope is again advanced up to the papilla, and the parent magnet was carefully inserted into the common bile duct with an pusher. For smaller one $(<4.2 \mathrm{~mm})$, the parent magnet can be directly inserted into the channel and then introduced into the common bile duct, even without papilla dilation (7). Under X-ray, the two magnets will attract each other once their positions are properly aligned (Figure 1C). (II) When the BAS is severely narrow, an cylindrical magnet with axial central hole is selected (Figure 1D). A guidewire is advanced through the slim stricture carefully and enter the duodenal cavity. The procedure is then switched to duodenoscopy; the guidewire in the duodenal cavity is grasped and led out of the body through the working channel; then EST and papilla dilation is done. The daughter and parent magnets are put over the two ends of guidewire (Figure 1E), and under X-ray monitoring, the magnets are pushed simultaneously to the stricture site to complete the mutual coupling (Figure $1 F$ ).

\section{Postoperative management}

An abdominal X-ray film is obtained on the first day after the operation and every 3-4 days thereafter. When the amount of drainaged bile is significantly reduced or the stool color turns yellow, cholangiography is required to confirm recanalization. If the biliary tract continuity is confirmed, multiple plastic stents or a fully covered metallic stent should be placed across the stricture for more than 6 months $(1,2,5-7)$.

\section{Precautions for MRT}

The technical difficulty mainly involves advancing the parent magnet through the duodenal papilla. EST, cylindrical balloon expansion, or a temporary fully covered metallic stent can be used for papilla expansion. Magnetic force, stricture length, and tissue features are the main factors for success. In the early stage after magnet coupling, sequential $\mathrm{X}$-rays are essential to confirm the distance changes between magnets. If separation occurs, another magnet can be added for either magnet to increase power (1). Before magnets removal, patients should avoid strong magnetic field area, so as to prevent the magnets from shifting or falling off.

\section{Prevention and treatment of complications of MRT}

The complications of MRT may include cholangitis, 

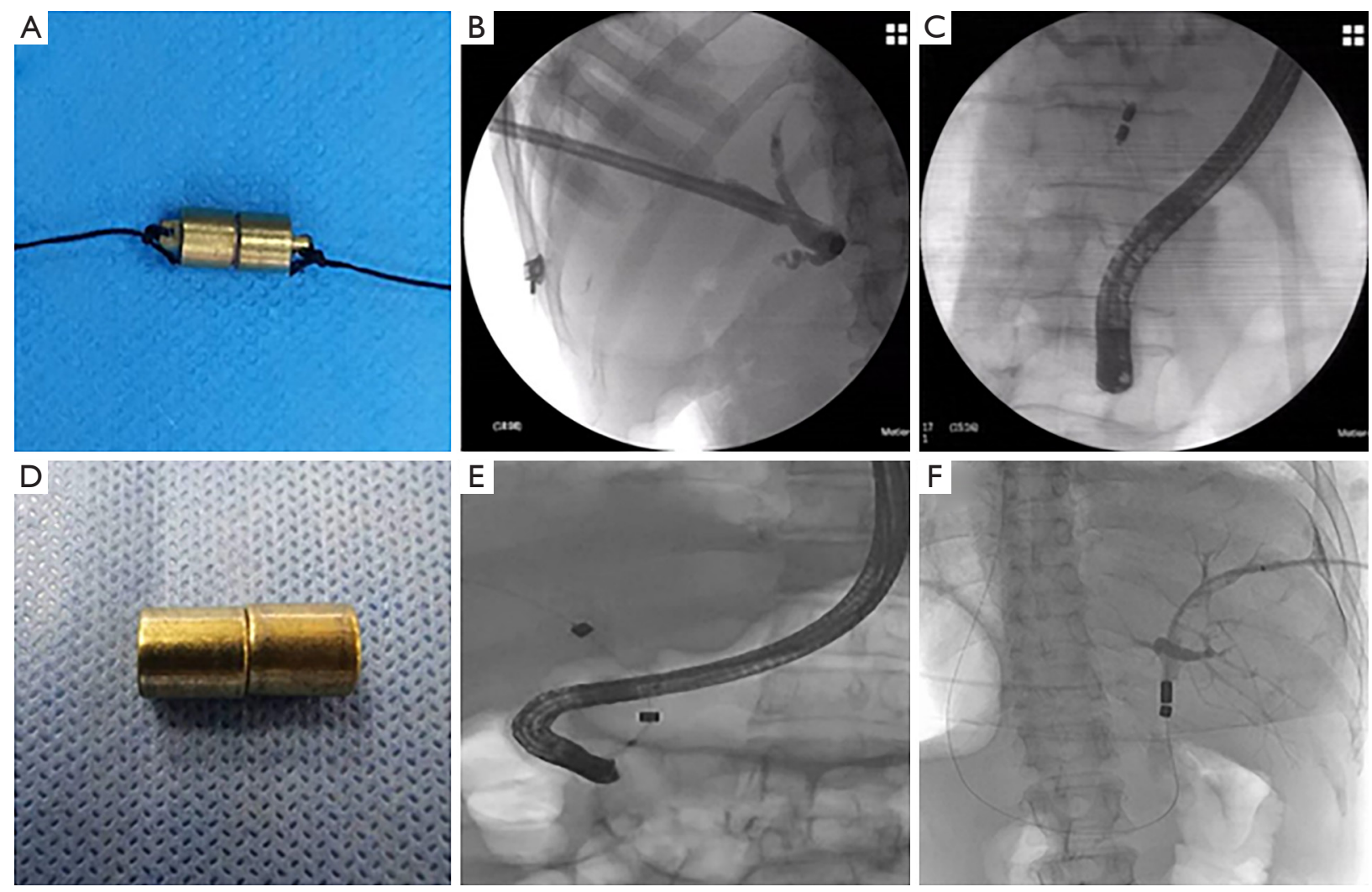

Figure 1 The magnets and methods used in MRT. (A) Cylindrical magnets with a tail at one end connected with a silk thread; (B) the daughter magnet was pushed to the superior end of stricture through the PTCD tract; (C) the parent magnet was advanced to the inferior end of stricture through papilla, and two magnet coupled with each other; (D) cylindrical magnets with an axial central hole; (E) a guide wire was inserted through the slim stricture, and two magnets were advanced to each other over the guide wire; (F) two magnet coupled with each other.

biliary leakage, bleeding and stricture recurrence. Sterile procedures in operation and proper drainage of the biliary tract post-operation are the keys to prevent cholangitis. Bile bacterial culture is useful for selection of antibiotics. Biliary tract bleeding may occur when the PTCD sinus tract is dilated or the stenosis is compressed and recanalized. The PTCD procedure should avoid injury of major hepatic blood vessels and tract dilation needs to wait for the sinus healing. Advancement of the parent magnet through the duodenal papilla is critical. It is recommended to use small magnets in combination with EST and papilla dilation. When advancing parent magnet to the narrow site, it should be gentle to reduce damage to the biliary tract. The compression of stricture tissue by magnets is a relatively slow process. The blood vessels between tissues are gradually closed, and the probability of bleeding is extremely low (1).

\section{Acknowledgments}

Funding: This work was supported by National Natural Science Foundation of China (grant number: 81470896).

\section{Footnote}

Provenance and Peer Review: This article was a standard submission to the journal Hepatobiliary Surgery and Nutrition. The article has undergone external peer review.

Conflicts of Interest: All authors have completed the ICMJE uniform disclosure form (available at https://hbsn. amegroups.com/article/view/10.21037/hbsn-20-800/coif). The authors have no conflicts of interest to declare.

Ethical Statement: The authors are accountable for all aspects of the work in ensuring that questions related 
to the accuracy or integrity of any part of the work are appropriately investigated and resolved.

Open Access Statement: This is an Open Access article distributed in accordance with the Creative Commons Attribution-NonCommercial-NoDerivs 4.0 International License (CC BY-NC-ND 4.0), which permits the noncommercial replication and distribution of the article with the strict proviso that no changes or edits are made and the original work is properly cited (including links to both the formal publication through the relevant DOI and the license). See: https://creativecommons.org/licenses/by-nc-nd/4.0/.

\section{References}

1. Li Y, Sun H, Yan X, et al. Magnetic compression anastomosis for the treatment of benign biliary strictures: a clinical study from China. Surg Endosc 2020,34:2541-50.

2. Jang SI, Kim JH, Won JY, et al. Magnetic compression anastomosis is useful in biliary anastomotic strictures after living donor liver transplantation. Gastrointest Endosc 2011;74:1040-8.

Cite this article as: Li Y, Zhang N, Lv Y; Scientific Committee of the Third International Conference of Magnetic Surgery. Expert consensus on magnetic recanalization technique for biliary anastomotic strictures after liver transplantation. HepatoBiliary Surg Nutr 2021;10(3):401-404. doi: 10.21037/ hbsn-20-800
3. Ersoz G, Tekin F, Bozkaya H, et al. Magnetic compression anastomosis for patients with a disconnected bile duct after living-donor related liver transplantation: a pilot study. Endoscopy 2016;48:652-6.

4. Marubashi S, Nagano H, Yamanouchi E, et al. Salvage cystic duct anastomosis using a magnetic compression technique for incomplete bile duct reconstruction in living donor liver transplantation. Liver Transpl 2010;16:33-7.

5. Okajima H, Kotera A, Takeichi T, et al. Magnet compression anastomosis for bile duct stenosis after duct-to-duct biliary reconstruction in living donor liver transplantation. Liver Transpl 2005;11:473-75.

6. Jang SI, Lee KH, Yoon HJ, et al. Treatment of completely obstructed benign biliary strictures with magnetic compression anastomosis: follow-up results after recanalization. Gastrointest Endosc 2017;85:1057-66.

7. Parlak E, Koksal AS, Kucukay F, et al. A novel technique for the endoscopic treatment of complete biliary anastomosis obstructions after liver transplantation: through-the-scope magnetic compression anastomosis. Gastrointest Endosc 2017;85:841-7. 